\title{
$O$ incentivo ao ergoengajamento dos atores sociais da rede de proteção da infância e do adolescente de Porto Seguro - BA: um relato de experiência do terceiro setor
}

\author{
Encouraging the ergoengagement of social actors in the child and adolescent protection \\ network of Porto Seguro-BA: an experience report from the third sector \\ Fomentar la participación de los actores sociales en la red de protección de niños y \\ adolescentes de Porto Seguro-BA: un informe de experiencia del tercer sector
}

\section{Danielle Ferreira Medeiro da Silva de Araújo ${ }^{\mathrm{i}}$ \\ Débora Caraúna da Motta Ribeiro ${ }^{\text {ii }}$ \\ Pétala Grecov Silva ${ }^{\text {iii }}$}

\begin{abstract}
Resumo: O objetivo do trabalho é expor uma experiência realizada no Terceiro Setor, que contou com a participação dos atores sociais que trabalham, de forma direta ou indireta, com a temática do trabalho infantil no Município de Porto Seguro, Estado da Bahia. A experiência, em execução, configura-se como uma proposta de ergoengajamento que privilegia a história de vida dos atores envolvidos no Projeto. A metodologia do trabalho é o relato de experiência do Projeto em execução do Terceiro Setor, pela OSC Instituto Mãe Terra.
\end{abstract}

Abstract: The objective of the work is to expose an experience carried out in the Third Sector, with the participation of social actors who work, directly or indirectly, with the theme of child labor in the city of Porto Seguro, State of Bahia. The experience, in execution, is configured as an ergoengagement proposal that privileges the life story of the actors involved in the Project. The methodology of the work is the experience report of the Project in execution of the Third Sector, by the OSC Instituto Mãe Terra.

Resumen: El objetivo del trabajo es exponer una experiencia llevada a cabo en el Tercer Sector, con la participación de actores sociales que trabajan, directa o indirectamente, con el tema del trabajo infantil en la ciudad de Porto Seguro, Estado de Bahía. La experiencia, en ejecución, se configura como una propuesta de compromiso sexual que privilegia la historia de vida de los actores involucrados en el Proyecto. La metodología del trabajo es el informe de experiencia del Proyec to en ejecución del Tercer Sector, por el OSC Instituto Mãe Terra.

Palavras-chave: ergoengajamento; atores sociais; terceiro setor.

Keywords: ergoengagement; social actors; third sector.

Palabras claves: ergoengajemento; actores sociales; tercer sector. 


\section{INTRODUÇÃO}

Este trabalho tem como objetivo apresentar a metodologia do Projeto Infância e Trabalho: Novas Alternativas de atuação, que tem por objetivo geral "criar um espaço de escuta e capacitação dos atores sociais que trabalham, de forma direta ou indireta, com a temática do trabalho infantil no Município de Porto Seguro, Estado da Bahia.”, aprovado pelo Termo de Fomento no 016/2048, de 13/12/2018, firmado entre o Instituto Mãe Terra e a SECRETARIA DE JUSTIÇA, DIREITOS HUMANOS E DESENVOLVIMENTO SOCIAL - SJDHDS do Governo do Estado da Bahia, oriundo do Edital de Chamamento Público CECA /SJDHDS/001/2018, de 04/10/2018, publicada no Diário Oficial Eletrônico do TCE-BA em 10/10/2018. A experiência, em execução, configura-se como uma proposta de ergoengajamento que privilegia a história de vida dos atores envolvidos no Projeto.

Para a execução do Projeto Infância e Trabalho: Novas Alternativas de Atuação foram planejadas 10 oficinas que têm sido realizada no ano de 2019 com a rede de proteção da criança e do adolescente de Porto Seguro - Bahia. Entre o público participante estão: Polícia Militar, Agentes de Proteção da Vara da Infância e Juventude, Conselho Tutelar, Agentes Comunitários de Saúde, Organizações Sociais, Movimento dos Trabalhadores sem TerraMST, Comunidade Cigana, Guarda Municipal, e gestores da Educação.

A metodologia das oficinas com duração de 4 horas organizou-se didaticamente em três momentos: sensibilização/acolhimento, escuta de casos e capacitação, objetivando analisar a complexidade dos casos que envolvam infância e trabalho, incentivando a construção coletiva de ações interventivas. Vale ressaltar, que em cada experiência pedagógica tal planejamento seguiu um caminho distinto suscitado pela criação de um espaço interdisciplinar de escuta sobre casos concretos que envolvam as situações de trabalho e infância. A metodologia do trabalho é o relato de experiência do Projeto em execução do Terceiro Setor, pela OSC Instituto Mãe Terra.

\section{O INCENTIVO AO ERGOENGAJAMENTO DURANTE AS OFICINAS DO PROJETO INFÂNCIA E TRABALHO}

Segundo a ergologia, entre o trabalho prescrito e o trabalho realizado existe uma distância ocupada pelo “aqui e agora”, que é um tempo movido por variáveis intrínsecas e extrínsecas ao Homem. $\mathrm{Na}$ atividade do trabalho, considerada como diálogo interior entre o corpo e a mente de quem trabalha, a dialética entre o trabalho prescrito e o realizado é formulada pelos saberes investidos e saberes constituídos. (TRINQUET, 2010). 
No projeto, o momento de sensibilização/acolhimento consistia na qualificação do indivíduo sobre si mesmo, o que para ergologia refere-se aos saberes investidos. Compreendido como os saberes investidos no corpo - si, “[...] 'corpo-si', árbitro no mais íntimo da atividade, [...] que não é um 'sujeito' delimitado, definido, mas uma entidade enigmática que resiste às tentativas de ser objetivado" (SCHWARTZ, DUC e DURRIVE, 2010e, p. 196).

No momento em que os atores de proteção eram convidados a se apresentarem, era pedido que atribuísse uma qualidade da sua personalidade que começasse com a primeira letra do seu nome. A escolha por esta forma de apresentação tinha por objetivo estimular o diálogo interno para melhor compreensão e ressignificação de características pessoais em recurso para o exercício do trabalho.

Uma situação que retrata o debate de normas e transgressões através do estimulo do diálogo interno a partir do reconhecimento de qualidades acerca de si mesmo, ocorreu em uma das oficinas na qual um participante apresentou como característica pessoal a rebeldia, no entanto não a reconhecia como qualidade ou como habilidade que pudesse agregar valor à realização do seu trabalho. A partir disso o objetivo do diálogo foi proporcionar a renormalização do papel da rebeldia para a mudança do status quo ou mesmo para se enfrentar situações de injustiças.

Em seguida eram apresentados alguns dados que foram coletados durante a execução do Projeto Filhos da Terra - Diagnóstico Situacional do Trabalho Infantil na cidade de Porto Seguro - BA, executado em 2018 pelo Instituto Mãe Terra, financiado pelo Instituto Itaú Social, o foco da atividade foi expor as dificuldades trazidas pelos adolescentes para realização do sonho profissional: falta de oportunidades; falta de condições econômicas; dificuldades de transporte; medo de não conseguir/falta de apoio da família; dificuldades nos estudos. E os sonhos: cursar o ensino superior em diferentes áreas (humanas, exatas, carreiras policiais e militares, área de saúde, etc.); auxiliar financeiramente a família; ser jogador/a de futebol.

A partir da visualização desses dados, os participantes eram convidados a rememorar seu caminho pessoal para a conquista profissional identificando quais dificuldades foram semelhantes às enfrentadas pelos adolescentes, foi perguntado: Como os seus sonhos influenciaram você e quais as realidades encontradas/enfrentadas para alcançá-los? Como você chegou até aqui? E como você pensa que poderia auxiliar para que as crianças e adolescentes possam alcançar os seus sonhos? 
Este convite de imersão em si mesmo, possibilita ao outro educar-se a partir do compartilhamento dos saberes que tem sobre si, o aprofundamento do que "si" é para promoção da empatia. Ou seja, "ninguém jamais poderá encerrá-lo em uma moldura, por mais sedutora que ela seja" (SCHWARTZ, DUC e DURRIVE, 2010e, p. 198). Neste sentido podemos dizer que para uma atuação ergológica da rede de proteção da criança e do adolescente é preciso abandonar o emolduramento que encerra o indivíduo no estigma de "quem não quer nada como a vida" passando a promover neste o resgate de saberes investidos e o reconhecimento de competências sobre si mesmo.

Fez também parte da metodologia a interação com o poder das palavras a partir da "convicção de que as palavras produzem sentido, criam realidades e, às vezes, funcionam como potentes mecanismos de subjetivação" (BONDÍA, 2002, p.21). Para aplicação desta concepção, foi apresentado o conceito de "bendizer", ou o mesmo que "palavra bem-dita"; "abençoar; fazer com que algo se torne próspero, abençoado. Enaltecer; falar coisas boas; abençoar algo ou alguém; dar a bênção. E "maldizer", ou o mesmo que "palavra mal-dita"; "Maledicência; fala maldosa; ação de quem difama. Difamar; falar mal de alguém; atacar a boa reputação ex.: ele maldizia os amigos pelas costas; preferia maldizer a elogiar. Amaldiçoar; desejar que o mau aconteça para falar de relações sociais respeitosas" (FERREIRA, s.d).

De acordo com Schwartz (2000) o "uso de si" é manifestação do "si" na relação com o trabalho, para tanto, tornar consciente a escolha de "bem dizer" ou "mal dizer" proporciona ao ator envolvido na rede de referência da criança e do adolescente a escolha de exercer a atividade laboral tendo como possibilidade escolher por si mesmo criar relações respeitosas dentro da dramática do uso de si. Segundo Schwartz (1988, P.104) "uma dramatiqué, portanto, o lugar de uma verdadeira micro-história, essencialmente inaparente na qual cada um se vê na obrigação de se escolher ou escolher orientar sua atividade de tal ou tal modo".

\section{CONSIDERAÇÕES FINAIS}

A importância deste saber investido, das histórias de vida de cada um dos participantes foi importante para se transpor as dificuldades de implementação fria das normas e das leis que direcionam o comportamento profissional dos mesmos. A sensibilização para o cuidado e valorização dos valores de cada ator foi fundamental para o segundo momento de capacitação, pois agregou sentido ao saber constituído. No polo do trabalho prescrito está o 
saber constituído, o saber formalizado nos planos de ensino, nas normas técnicas, organizacionais, nos softwares, nas atribuições do cargo, etc., ou seja, são os conhecimentos sistematizados utilizados para orientar de modo generalizável a atividade do trabalho (TRINQUET, 2010). Esse saber foi explorado no momento da "capacitação" orientado pela pesquisa sobre as atribuições profissionais, a cultura e a história de cada público participante buscando promover o diálogo interno através da dialética entre o saber investido invocado no momento de sensibilização/acolhimento e o saber constituído das atribuições profissionais, ampliando espaços para novas estratégias de atuação.

As principais estratégias construídas no processo dialógico das oficinas foram: 1. Continuidade dos estudos e o uso de base epistemológica do Sul, que privilegie autores decoloniais e a ecologia de saberes na produção acadêmica dos professores; 2. Construção de relatos de experiências que valorizem a infância dos sem-terrinhas, ampliando a discussão sobre as pluralidades de infâncias; 3. Divulgação em eventos científicos sobre a importância da agroecologia para a infância no MST, como forma de diminuição dos preconceitos e criminalizações que envolvem a atuação dos movimentos sociais no país; 4. Enfrentamento do racismo institucional a partir de um novo olhar que leve em conta o reconhecimento das pluralidades de infâncias em suas mais diversas situações de desigualdades sociais e/ou diversidades culturais; 5 . Atividades preventivas/ informativas em espaços escolares ou comunitários com foco no compartilhamento das histórias de vida dos próprios policiais, com a finalidade de se motivar as crianças e adolescentes a superarem suas dificuldades, permanecerem na escola e a optarem pelo caminho da educação; 6 . Atuação positiva, nãoviolenta, em situações que não requeiram o uso legítimo da força física; 7. Capacitação continuada para compreender aspectos sociais, culturais, psicológicos, biológicos da criança e do adolescente, ou seja, aprender mais para atuar melhor; 8. Ouvir com sensibilidade, compreender o outro, não desistir de ninguém, tratar com humanidade ajuda no entendimento das razões dos conflitos, acolher e não rejeitar; 9. Atuação positiva, nãoviolenta, sendo flexível aos contextos, mediar conflitos, oferecer informações que possam ajudar em novas escolhas/oportunizar outros caminhos; 10. Criar um catálogo de recursos comunitários para melhor visualização dos parceiros no território (como OSC, associações de moradores e instituições religiosas) que atuem com atendimentos e/ou projetos sociais, educacionais ou culturais; 11. Buscarparcerias institucionais com Faculdades e Universidades para a sistematização de dados e construção da memória institucional do Conselho Tutelar no Município, apresentar resultados e relatos de experiências em eventos acadêmicos, atuar de forma preventiva através da produção de materiais informativos; 12. Intercâmbio e 
capacitação em gerenciamento de projetos e captação de recursos das organizações sociais no território como forma de fortalecere ampliar a ação, principalmente em locais periféricos; 13. Eventos de valorização de cultura cigana em âmbito público e comunitário, utilizando equipamentos como o Centro de Cultura Municipal; 14. Atividades em âmbito escolar para discutir relações étnico-raciais, com foco na valorização da cultura negra, indígena e cigana; 15. Fortalecimento institucional da escola cigana através de parcerias com instituições públicas, privadas e educacionais para atuar junto ao acesso à educação e direitos das mulheres ciganas.

\section{REFERÊNCIAS}

BONDÍA. Carlos Larrosa. Notas sobre a experiência e o saber de experiência.

Trad. João Wanderley Geraldi. Revista Brasileira de Educação. Jan/Fev/Mar/Abr. 2002.

TRINQUET, P. Trabalho e Educação: o método ergológico. Revista HISTEDBR, Campinas, v. 10, n. número especial, p. 93-113, ago. 2010.

SCHWARTZ, Y. Os ingredientes da competência: um exercício necessário para uma questão insolúvel. Educação \& Sociedade, Campinas, v. 19, n. 65, p. 101 -140, dez. 1998. Trabalho e uso de si. Pro-Posições, São Paulo, v. 1, n. 5, p. 34-50, jul. 2000 b. Uso de si e competência. In: SCHWARTZ, Y.; DURRIVE, L. (Org.). Trabalho \& Ergologia: conversas sobre a atividade humana. 2. ed. Niterói: EdUFF, 2010e. 205-221 p.

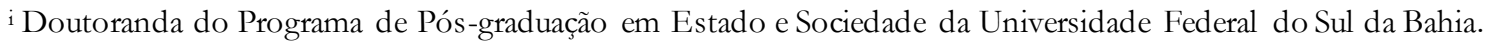
Gestora social e fundadora da ONG Gerando Vida E-mail: dannymedeiro@hotmail.com

ii Especialista em Avaliação Psicológica pelo IPOG. Formação na Abordagem Centrada na Pessoa pelo Instituto Diabases da BA. Formada em Psicologia pela Faculdade Castro Alves. E-mail: caraúna_motta@hotmail.com

iii Discente em Pedagogia pela Faculdade Nossa Senhora de Lourdes (FNSL). E-mail: petalagrecov@gmail.com
} 